involved. Semantic or contextual variation improves recall, whereas modality variation does not. The work on release from PI (Hopkins, Edwards, \& Gravelek, 1971; Murdock \& Carey, 1972) also provides evidence that modality changes and semantic changes have different effects. Modality effects may be typical of those for physical variations or, alternatively, they may well be peculiar to modality alone.

\section{REFERENCES}

Bevan, W., \& Dukes, W. F. Stimulus-variation and recall: The role of belongingness. American Journal of Psychology, 1967, 80, 309-312.

Bjork, R. A., \& Allen, T. W. The spacing effect: Consolidation or differential encoding. Journal of Verbal Learning \& Verbal Behavior, 1970, 9, 567-572.

Bower, G. H. Stimulus-sampling theory of encoding variability. In E. Martin and A. W. Melton (Eds.), Coding processes in human memory. New York: Halsted Press, 1972.

D'Agostino, P. R., \& De Remer, P. Repetition effects as a function of rehearsal and encoding variability. Journal of Verbal Learning \& Verbal Behavior, 1973, 12, 108-113.

Glanzer, M., \& Duarte, A. Repetition between and within languages in free recall. Journal of Verbal Learning \& Verbal Behavior, 1971, 10, 625-630.
Hintzman, D. L., Block, R. A., \& Inskeep, N. R. Memory for mode of input. Journal of Verbal Learning \& Verbal Behavior, 1972, 11, 741-749.

Hopkins, R. H., Edwards, R. E., \& Gavelek, J. R. Presentation modality as an encoding variable in short-term memory. Journal of Experimental Psychology, 1971, 90, 319-325.

McCormack, P. D., \& Carboni, N. L. Lag invariance with forced encodings in free recall. Canadian Journal of Psychology, 1973, 27, 144-151.

Madigan, S. A. Intraserial repetition and coding processes in free recall. Journal of Verbal Learning \& Verbal Behavior, 1969, 8, 828-835.

Madigan, S., \& Doherty, L. Retention of item attributes in free recall. Psychonomic Science, 1972, 27, 233-235.

Melton, A. W. The situation with respect to the spacing of repetitions and memory. Journal of Verbal Learning \& Verbal Behavior, 1970, 9, 596-606.

Murdock, B. B., Jr., \& Carey, S. T. Release from interference in single-trial free recall. Journal of Verbal Learning \& Verbal Behavior, 1972, 11, 398-402.

Rundus, D. Analysis of rehearsal processes in free recall. Journal of Experimental Psychology, 1971, 89, 63-77.

(Received for publication January 18, 1974.)

\title{
Effects of shock intensity on speed and response competition in the escape training of neonatal and infant rats
}

\author{
JAMES R. MISANIN, SHERYL HARDY, and JANET GOODYEAR \\ Susquehanna University, Selinsgrove, Pennsylvania 17870 \\ and \\ Z. MICHAEL NAGY
Bowling Green State University, Bowling Green, Ohio 43402
}

\begin{abstract}
Rats, 3-11 days old, were given 25 escape training trials in a straight alley with .1, .2, or .4-mA $60-\mathrm{Hz}$ ac shock as the motivating stimulus. The results indicated that the younger the rat or the more intense the shock, the less likely escape training was to be completely effective. On .1 mA, only the 7 - to 11-day-old Ss showed an intrasession speed increase, and on .4 mA, only the 11-day-olds showed such an increase. The 7- to 11-day-old Ss were also the only Ss to increase speed as shock intensity increased. Response competition, on the other hand, decreased over training trials for all age groups on both .1 and $.2 \mathrm{~mA}$, but only the 5- and 7-day-old Ss showed such a decrease on .4 mA. For all age groups, however, response competition varied inversely with shock intensity.
\end{abstract}

A number of studies has suggested that turning is a reaction apparently high on the neonatal rat's response hierarchy when it encounters an aversive stimulus. Gard, Hard, Larsson, and Peterson (1967), for example, 


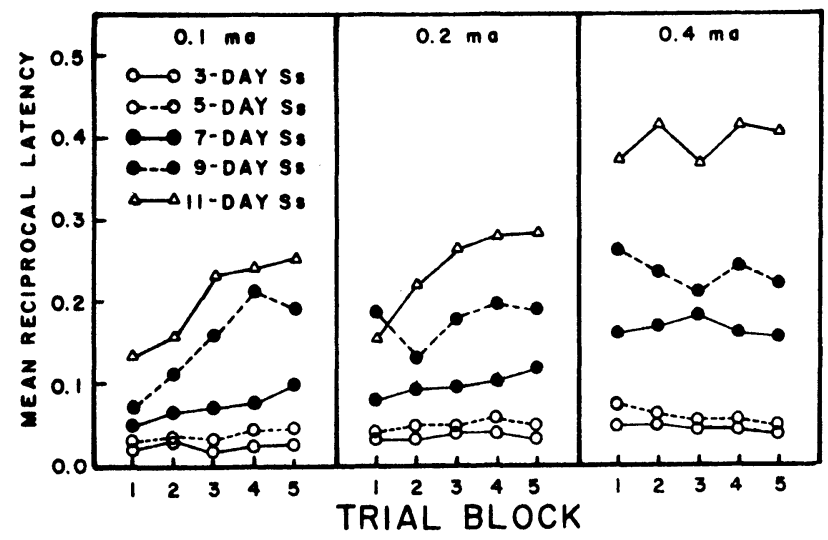

Fig. 1. Mean speed (reciprocal latency) per five-trial block as a function of age and shock level.

exposed rats to ammonia fumes and found, with the exception of head and foreleg movements, turning (pivoting) to be the prevalent response. Similarly, Misanin, Nagy, and Weiss (1970) reported that the first response to shock in the majority of neonatal rats tested was a 180-deg turn. Bolles and Woods (1964) noted a similar behavior when neonatal rats fell or were dragged from the nest, an experience which may have been aversive since the neonatal rat is poikilothermic (Adolf, 1957) and, hence, body temperature tends to drop quickly outside of the nest.

Some investigators (Simonson, Sherwin, Anilane, Yu, \& Chow, 1969) have referred to this turning reaction as "purposeless locomotion" (p. 20), whereas others (Altman, Sudarshan, Das, McCormick, \& Barnes, 1971) have considered it an "early, abortive form of locomotion" (p. 101), and have used it as a developmental index in studies on the emergence of locomotor and exploratory behaviors. Gard et al (1967) have cautioned, however, that description of development should not be based solely on response patterns, but should also include a specification of the stimulus that produced the response. These investigators found that, as the aversiveness of the stimulus increased, turning behavior in infant rats not only emerged at an earlier age but also reached a peak and dropped off at an earlier age than it normally would have. In their experiment, the rat's behavior exerted no influence on the presence or absence of the aversive stimulus. Where such an influence would exist, e.g., in an instrumental training situation, the role of intensity of aversive stimulation in the turning behavior of neonatal and infant rats has not been investigated. In such a situation, a totally different response pattern may emerge. In a straight-alley shock escape situation, for example, speed of escape would be expected to increase with an increase in shock intensity; concomitantly, turning, which would compete with the escape response, might decrease. Thus, this study examined the effect of varying shock intensity on response competition (turning) and speed in the escape training of neonatal and infant rats.

\section{METHOD}

\section{Subject}

Twenty-one male and 21 female Wistar albino rats at each of five age levels $(3,5,7,9$, and 11 days) were used. The rats were selected from 30 litters born in the Susquehanna University animal colony. The mean and standard deviation of litter size were 10.8 and 2.8, respectively. No two animals in any age-sex-shock group came from the same litter. All rats were kept on pine shavings in $46 \times 23 \times 13 \mathrm{~cm}$ polyethylene cages with their mothers from birth; mothers had free access to food and water.

\section{Apparatus}

The straight alley has been previously described (Misanin et al, 1970). It was a $25 \times 6 \times 10 \mathrm{~cm}$ aluminum alley with a grid floor. The grids, 1-mm-diam stainless steel rods, were mounted in acrylic at $3-\mathrm{mm}$ intervals, center to center. A removable door located $5 \mathrm{~cm}$ from one end of the alley formed the startbox. A Harvard Instrument shock generator and scrambler (Model HI 3121) were used to deliver shock to the grids.

\section{Procedure}

Seven male and seven female rats of each age were randomly assigned to each of three shock intensity groups, .1, .2, and $.4 \mathrm{~mA}$. Each animal was given 25 shock escape training trials with $45-\mathrm{sec}$ intertrial intervals. Each rat was placed in the startbox facing the goal end of the alley (start position) $15 \mathrm{sec}$ before the start of each trial. A trial began with the removal of the door and the simultaneous application of $60-\mathrm{Hz}$ ac shock to the grids. Shock and trial ended when the rat touched the wall of the alley opposite the startbox. If the animal failed to do this within $180 \mathrm{sec}$, it was gently forced to the end wall, at which time shock was terminated. At shock offset, the rat was removed from the alley and held in E's hand for $30 \mathrm{sec}$.

The time it took the rat to traverse the alley (response latency) was recorded to the nearest $.1 \mathrm{sec}$ for each trial. Also recorded was the number of competing responses (turns) on each trial. A competing response was defined as $180-$ deg turn from the start position. Following such a turn, a return to the start position, i.e., facing the goal, was necessary before another competing response could be made and recorded.

\section{RESULTS}

A reciprocal transformation of the latency data (speed measure) was averaged over five-trial blocks for each age-sex-shock group and analyzed as a 2 by 3 by 5 by 5 design, with sex, shock level, age, and trial block the factors considered. The analysis showed significant main effects of age $(\mathrm{F}=105.37, \mathrm{df}=4 / 180, \mathrm{p}<.0005)$, shock level $(\mathrm{F}=29.76, \mathrm{df}=2 / 180, \mathrm{p}<.0005)$, and trial block $(F=11.89, \mathrm{df}=4 / 720, \mathrm{p}<.0005)$. Significant interactions of Age by Trial Block $(\mathrm{F}=3.93$, $\mathrm{df}=16 / 720, \mathrm{p}<.0005)$ and Shock Level by Trial Block $(\mathrm{F}=5.61, \quad \mathrm{df}=8 / 720, \mathrm{p}<.0005)$ also obtained. Figure 1 depicts the results with sex ignored. All age groups except the 3 and 5-day groups increased speed of escape as shock intensity increased (Fs $\geqslant 12.17$, $\mathrm{df}=8 / 180$, ps $<.0005$ ). Individual comparisons within each age-shock group between Trial Blocks 1 and 5 indicated that only the 11-day Ss were consistent over 


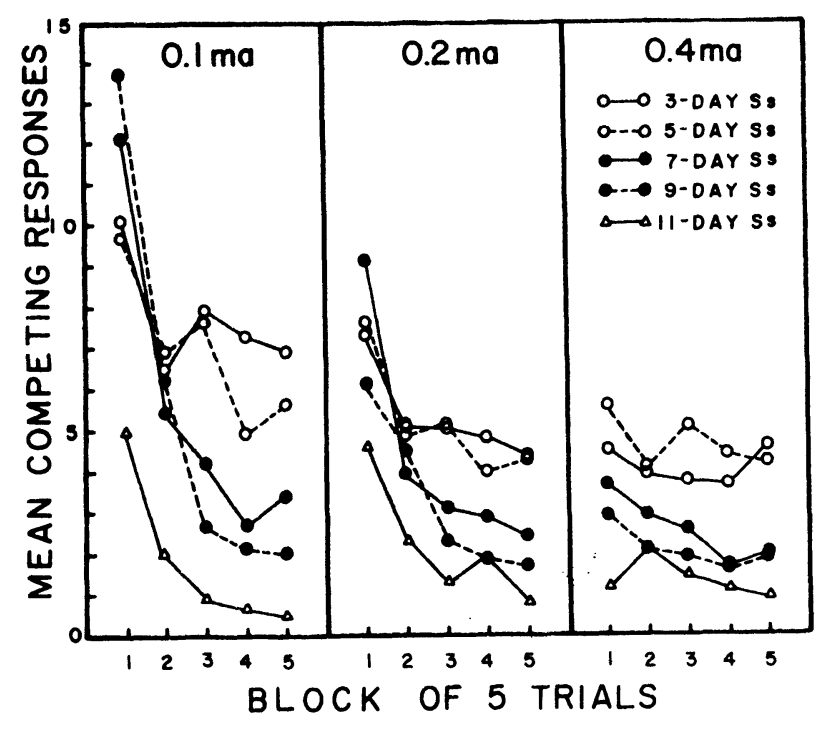

Fig. 2. Mean competing responses (180-deg turns) per five-trial block as a function of age and shock level.

all shock levels in showing an intrasession speed increase (Fs $\geqslant 1.78, \mathrm{df}=32 / 720$, ps $<.025)$. The 3- and 5-day Ss showed no intrasession speed increase at any shock level $(F s \leqslant 1.13, \mathrm{df}=32 / 720, \mathrm{p}>.1)$. In addition to the 11-day Ss, the 7- and 9-day-olds showed an increase in speed over trial blocks at the $.1-\mathrm{mA}$ level $(\mathrm{Fs} \geqslant 5.69$, $\mathrm{df}=32 / 720$, ps $<.0005)$; the 7 -day Ss also increased speed on $.2 \mathrm{~mA}(\mathrm{~F}=2.94, \mathrm{df}=32 / 720, \mathrm{p}<.0005)$.

Competing responses per five-trial block were also analyzed as a 2 by 3 by 5 by 5 design. Significant main effects of age $(F=27.10, d f=4 / 180, p<.0005)$, shock level $(\mathrm{F}=27.22, \mathrm{df}=2 / 180, \mathrm{p}<.0005)$, and trial block $(\mathrm{F}=74.50, \mathrm{df}=4 / 720, \mathrm{p}<.0005)$ obtained. The Shock Level by Trial Block $(\mathrm{F}=13.29, \mathrm{df}=8 / 720)$, Age by Trial Block $(\mathrm{F}=4.22, \mathrm{df}=16 / 720)$, and Age by Shock Level by Trial Block $(\mathrm{F}=1.57, \mathrm{df}=32 / 720)$ interactions were also significant $(\mathrm{ps}<.05)$. These results are depicted in Fig. 2. Sex is again ignored, since it failed to have a significant main effect or interact significantly with any other factor(s).

At both the .1- and .2-mA levels, all age groups significantly decreased turning over trial blocks $(\mathrm{Fs} \geqslant 8.0, \mathrm{df}=32 / 720$, ps $<.0005)$. At the $.4-\mathrm{mA}$ level, however, only the 5- and 7-day Ss showed a decrease $(F s \geqslant 2.00, \mathrm{df}=32 / 720$, ps $<.005)$. The failure of the older animals to show a decrease is due, apparently, to a low initial (Block 1) baseline. All age groups, howevor, showed a decrease in 180-deg turns as shock intensity increased $(\mathrm{Fs} \geqslant 2.36, \mathrm{df}=8 / 180$, ps $<.025)$.

Comparisons across ages showed that the 3-day Ss failed to differ from the 5-day Ss, and the 7-day Ss failed to differ from the 9-day Ss at all shock levels (Fs $\leqslant 1.72$, $\mathrm{df}=8 / 180$, ps $>.05$ ). With the exceptions of the failure of the 5- and 7-day groups to differ at the .2-mA level and the failure of the 9- and 11-day groups to differ at
$.4 \mathrm{~mA}$, the remaining between-group comparisons yielded significant differences $(F s \geqslant 2.14, \mathrm{df}=8 / 180$, ps $<.05)$.

\section{DISCUSSION}

Kukleta's research (1968) has delineated two components of a learned escape reaction. One component can be defined as determining the direction of escape; the other is closely related to motor functions and determines a mode of behavior necessary to the most efficient execution of the response. In essence, escape learning involves both learning the direction of escape and learning to go directly to the goal, or the form of the response. This latter learning, then, requires the elimination of competing tendencies.

Previous research on escape training in infant rats (Misanin, Haigh, Hinderliter, \& Nagy, 1973) has suggested that a decrease in competing turns unaccompanied by an increase in speed of escape is indicative of learning only a single component of the escape reaction, viz., the form of the response. If so, then the present data indicate that the younger the rat or the more intense the shock, the less likely escape training in infant rats is to be completely effective; only the 7- to 11-day-olds increased speed of escape as training progressed at the .1-mA level and only the 11-day Ss did so at the .4-mA level. The 7- to 11-day Ss were also the only Ss that increased speed of escape as shock intensity increased. In contrast to this age-related effect of shock intensity on the quantitative characteristic of escape, increasing the intensity of aversive stimulation had a similar effect at all age levels on the qualitative characteristic of escape. In this respect, increasing the intensity of an aversive stimulus in an instrumental training situation has a different effect on the turning reaction of infant rats than it does in a situation where the rat's behavior exerts no influence on the presence or absence of the aversive stimulus. In this latter situation, increasing the level of aversive stimulation has been shown to increase the turning behavior of rats 1-7 days of age, but to have no effect or a decremental effect on turning in older (8-12 days) animals (Gard et al, 1967). In the present study, on the other hand, increasing the intensity of an aversive stimulus led to a decrease in the turning reaction at all ages (3-11 days) investigated. These results thus suggest an addendum to the Gard et al (1967) caution: The description of development should not be based solely upon response patterns, but should also include a specification of the stimuli that produced the response and the situation in which the response occurred.

\section{REFERENCES}

Adolf, E. F. Ontogeny of physiological regulations in the rat. Quarterly Review of Biology, 1957, 32, 89-137.

Altman, J., Sudarshan, K., Das, D. D., McCormick, N., \& Barnes, D. The influence of nutrition on neural and behavioral development: III. Develooment of some motor, particularly locomotor, patterns during infancy. Developmental Psychobiology, 1971, 4, 97-114.

Bolles, R. C., \& Woods, P. J. 'Ine ontogeny of behaviour in the albino rat. Animal Behaviour, 1964, 12, 427-441.

Gard, C., Hard, E., Larsson, K., \& Peterson, V. The relationship between sensory stimulation and gross motor behaviour during postnatal development in the rat. Animal Behaviour, $1967,15,563-567$.

Kukleta, M. Memory components of shock escape reaction in rat. Phvsiology \& Behavior, 1968, 3, 773-7 76

Misanin, J. R., Haigh, J. M., Hinderliter, C. F., \& Nagy, Z. M. Journal of Comparative \& Physiological Psychology, 1973, 85, 570-580.

Misanin, J. R., Nagy, Z. M., \& Weiss, E. M. Escape behavior in neonatal rats. Psychonomic Science, 1970, 18, 191-192.

Simonson, M., Sherwin, R. W., Anilane, J. K., Yu, W. Y., \& Chow, B. F. Neuromotor development in progency of underfed mother rats. Journal of Nutrition, 1969, 98, 18-24.

(R eceived for publication July 6, 1974.) 